Arq. Bras. Med. Vet. Zootec., v.56, n.3, p.312-319, 2004

\title{
Fixação de enxerto cutâneo em malha de espessura total com sutura ou cola de fibrina
}

\author{
[Fixation of full-thickness mesh skin using suture or fibrin glue] \\ M.S.P. Amaral ${ }^{1}$, S.C. Rahal ${ }^{2}$, V. Dal-Pai ${ }^{1}$, S.R.C.S. Barraviera ${ }^{3}$, A.F.M. Lima $^{2}$, A.J. Crocci ${ }^{4}$ \\ ${ }^{1}$ Faculdade de Medicina Veterinária - UNOESTE \\ Rodovia Raposo Tavares, km 572, Bairro Limoeiro \\ 19067-175 - Presidente Prudente, SP \\ ${ }^{2}$ Faculdade de Medicina Veterinária e Zootecnia - UNESP - Botucatu, SP \\ ${ }^{3}$ Faculdade de Medicina - UNESP - Botucatu, SP \\ ${ }^{4}$ Instituto de Biociências - UNESP - Botucatu, SP
}

\begin{abstract}
RESUMO
Avaliou-se a influência da cola de fibrina, derivada do veneno de serpente, na fixação e integração de enxerto de pele. Foram utilizados nove cães, sem raça definida, com peso médio de $15 \mathrm{~kg}$. Foi induzida ferida de $4 \times 4 \mathrm{~cm}$ de área, na face crânio-proximal dos antebraços direito e esquerdo. Um enxerto de espessura total foi colhido da região torácica e expandido por meio de expansor de pele. No membro direito o enxerto foi estabilizado no leito receptor por meio de pontos isolados simples; no esquerdo foi fixado pela aplicação de cola de fibrina e oito pontos de sutura. O sítio doador foi fechado empregando-se retalho cutâneo bipediculado. As bandagens do leito receptor foram oclusivas e não aderentes e aplicou-se pomada de neomicina com bacitracina. A troca de bandagens ocorreu diariamente até o sétimo dia de pósoperatório e, posteriormente, a cada três dias. A área de sobrevivência do enxerto foi obtida pela subtração das áreas não viáveis e total medidas com fotomicroscópio Nikon conectado a um sistema de análise de imagem KS-300 aos três, sete, 15 e 30 dias de pós-operatório. Para a avaliação microscópica, a área do enxerto foi colhida em três animais aos sete, 15 e 30 dias de pós-operatório. Não houve diferença entre momentos de avaliação e técnicas de fixação quanto à área de enxerto viável. Os enxertos fixados com cola apresentaram estágio de reparação mais avançado em todos os momentos. Concluiu-se que a cola de fibrina derivada do veneno de serpente tem moderado poder adesivo e, pela análise microscópica, favorece a integração do enxerto cutâneo em malha de espessura total.
\end{abstract}

Palavras-chave: cola de fibrina, enxerto cutâneo, sutura, serpente

\begin{abstract}
The purpose of this study was to evaluate the efficiency of fibrin glue, derived from snake venom, on fixation and integration of skin graft. Nine crossbred dogs, with average weight of $15 \mathrm{~kg}$ were used. Wounds measuring $4 \times 4 \mathrm{~cm}$ were induced at the cranioproximal aspect of the right and left forelimb. Full-thickness skin grafts were harvested from thoracic area, and meshed with a commercial mesh dermatome. The graft was secured to the recipient bed using several simple interrupted sutures on the right forelimb. On the left forelimb fibrin glue and eight simple interrupted sutures were used. The bed was closed using bipedicle advancement flap. The non-adherent occlusive bandage and neomycinbacitracin ointment were used on receptor bed. The bandage was changed every day until the seventh day postoperative and every three days afterwards. The graft survival area was obtained by subtraction of total and nonviable areas measured with a Nikon Photomicroscope connected to a KS-300 image analysis system at 3, 7, 15 and 30 days postsurgically. For microscopic evaluation, the skin graft, recipient bed and adjacent surrounding skin were collected at 7,15 and 30 days postsurgery. No statistical difference was detected for the viable graft area, in each evaluation moment and between fixation methods. However, based on microscopic evaluation, fibrin glue enhanced the tissue repair process in all evaluation moments. It was possible to conclude that fibrin glue derived from snake venom
\end{abstract}

Recebido para publicação em 9 de dezembro de 2002

Recebido para publicação, após modificações, em 18 de junho de 2003

E-mail: savio@vet.unioeste.br 
has moderate adhesive capacity, and, based on microscopic examination, improves the integration of fullthickness mesh skin grafts.

Keywords: fibrin glue, skin graft, suture, snake

\section{INTRODUÇÃO}

O enxerto em malha de espessura total é um fragmento de pele com várias incisões paralelas, cujo tecido subcutâneo deve ser removido para não interferir na revascularização (Swaim, 1990). Segundo Pope (1990), o grau pelo qual ele será expandido depende da quantidade de pele doadora disponível e da condição do leito receptor. Se suficiente tecido doador estiver disponível, enxertos, minimamente expandidos ou não expandidos, devem ser utilizados pelo aspecto cosmético, pelo fato de os interstícios cicatrizarem por epitelização, resultando em ilhas sem pêlo. Embora não necessário (Pavletic, 1993), o tecido de granulação saudável proporciona o melhor tipo de leito para esse tipo de enxerto (Swaim et al., 1984).

Mudanças freqüentes de bandagens são necessárias com enxerto em malha, porque a drenagem do leito receptor pode causar maceração da pele ou permitir que bactérias penetrem através da bandagem e infectem a ferida (Pope, 1988). Segundo Pope (1998), as trocas de bandagens não devem ultrapassar 48 horas. Entretanto, se grande quantidade de drenagem é prevista, a troca pode ser realizada dentro de 24 horas, com aumento no risco da ruptura do selo de fibrina entre o leito recipiente e o enxerto. Conforme Hedlund (1997), o perigo do acúmulo de fluido é maior do que o risco de mover o enxerto durante a manipulação da bandagem. É importante que o fluído drene longe da superfície, visando prevenir maceração entre enxerto e pele circundante (Pope, 1990).

Swaim et al. (1984) utilizaram enxerto em malha no membro de 10 cães, fixados, com e sem expansão, por meio de suturas interrompidas. As bandagens foram mudadas diariamente, por 21 dias. $\mathrm{Na}$ fase inicial da cicatrização, o tecido de granulação cresceu, através das fendas, mais no enxerto expandido do que no não expandido, o que proporcionou ao não expandido um aspecto cosmético. Hemorragia, que ocorreu dentro de 48 horas, foi drenada mais facilmente pelos enxertos expandidos. Não houve diferença entre os enxertos quanto ao crescimento de pêlos.

O uso do adesivo biológico de fibrina é conhecido desde 1909, quando Bergel documentou o efeito hemostático do pó de fibrina. Entretanto, apenas em 1944 Cronkite et al. e Tidrick e Warner efetivamente combinaram fibrinogênio e trombina para o uso clínico na fixação do enxerto de pele (apud Saltz et al., 1991). Sua capacidade em aumentar a força da linha de incisão pós-operatória facilita a cicatrização (Lindsey et al., 1990). Apresenta excelente tolerância tecidual e é reabsorvido durante a cicatrização da ferida, sem reação de corpo estranho ou fibrose extensa (Brennan, 1991).

Segundo Lerner e Binur (1990), a cola de fibrina reduz o tempo operatório e aumenta a sobrevivência de enxertos de pele. Aplicada no enxerto e em suas margens, auxilia tanto na fixação deste como na hemostasia da ferida. Ela tem sido usada para eliminar o espaço morto e aumentar a probabilidade de o enxerto ser revascularizado e diminuir o número de suturas em cirurgias cosméticas e reconstrutivas (Silver et al., 1995).

Piechotta e Flemming (1983) utilizaram a cola de fibrina em 304 pacientes humanos submetidos a uma variedade de cirurgias plásticas. Os resultados foram melhores com o produto, com mais conforto para o paciente. Não foram observados casos de hematoma.

Como o fibrinogênio, componente de colas biológicas comerciais, é derivado, em geral, do plasma humano, há riscos de transmissão de doenças virais (Lindsey, 1990). A cola de fibrina desenvolvida pelo Centro de Estudos de Venenos de Animais Peçonhentos (CEVAP) provem do veneno de serpente, sendo constituída por um crioprecipitado enriquecido com fibrinogênio humano, bovino, bubalino ou eqüino e uma fração tipo trombina do veneno de cobra (Iuan et al., 1995; Viterbo et al., 1993). Stolf (1998) a utilizou em 21 pacientes caucasianos, portadores 
de tumores cutâneos na região nasal. Para a síntese cutânea da área doadora, isto é, o sulco nasogeniano, o autor usou adesivo de fibrina no lado direito e sutura do lado esquerdo. $\mathrm{Na}$ avaliação tardia, o aspecto da cicatriz foi excelente no lado da cola e bom no da sutura. Ele teve capacidade adesiva total de $66,7 \%$ e parcial de $33,3 \%$, constituindo-se em método alternativo na cirurgia cutânea.

Este trabalho teve por objetivo avaliar a eficácia da cola de fibrina, derivada do veneno de serpente, na fixação e integração de enxertos cutâneos em cães.

\section{MATERIAL E MÉTODOS}

A Comissão de Ética em Experimentação Animal da Faculdade de Medicina Veterinária e Zootecnia - Unesp Botucatu aprovou o desenvolvimento deste trabalho.

Foram utilizados nove cães, sem raça definida, adultos, com peso médio de $15 \mathrm{~kg}$, alocados em jaulas individuais, onde receberam água e ração comercial ad libitum. Após jejum prévio de 12 horas, foram tranqüilizados com acepromazina ${ }^{1}$, na dose de $0,2 \mathrm{mg} / \mathrm{kg}$, por via subcutânea, e receberam buprenorfina, na dose de $10 \mu \mathrm{g} / \mathrm{kg} / \mathrm{subcutânea}^{2}$. Decorridos 30 minutos, a anestesia foi induzida e mantida com pentobarbital sódico ${ }^{3}$, na dose de $15 \mathrm{mg} / \mathrm{kg}$, por via venosa.

Inicialmente os cães foram posicionados em decúbito lateral direito e as regiões do antebraço esquerdo e torácica lateral esquerda (área doadora) preparadas para cirurgia asséptica. Foi induzida ferida de $4 \times 4 \mathrm{~cm}$ de área, na face crânio-proximal do antebraço esquerdo. Um enxerto de espessura total foi colhido da região torácica esquerda, baseando-se em um molde de papel, feito a partir do leito receptor (ferida antebraço). Após a colheita, o enxerto foi preso entre os dedos indicador e polegar, removendose o tecido subcutâneo com o emprego de

${ }^{1}$ ACEPRAN 0,2\% - Univet S.A. - Rua Clímaco Barbosa, 700 - São Paulo, SP.

2 TENGESIC - Indústria Química e Farmacêutica Schering Plough S/A - Estrada dos Bandeirantes, 3091 - Rio de Janeiro.

${ }^{3}$ HYPNOL 3\% - Cristália - Rodovia Itapira-Lindóia, km 14 Itapira, SP. tesoura, até a visualização dos folículos pilosos. $\mathrm{O}$ enxerto foi expandido por meio de expansor de pele $^{4}$ e suturado à pele periférica do leito receptor, com o emprego de pontos isolados simples, com fio de náilon 3-0. As margens do enxerto sobrepuseram as da ferida. A síntese do sítio doador foi com retalho cutâneo bipediculado. Os animais foram reposicionados em decúbito lateral esquerdo e o antebraço direito foi submetido a procedimento similar ao realizado no antebraço esquerdo. A diferença foi a estabilização do enxerto pela aplicação de cola de fibrina, derivada do veneno de serpente (Crotalus durissus terrificus), no leito receptor (seis a oito gotas) e oito pontos de sutura, na pele periférica, com fio de náilon 3-0.

Os cães receberam enrofloxacina na dose de $5 \mathrm{mg} / \mathrm{kg}$, por via subcutânea, a cada 24 horas, iniciando 12 horas antes do procedimento cirúrgico e por mais sete dias. No período pósoperatório foi utilizada buprenorfina na dose de $10 \mu \mathrm{g} / \mathrm{kg} / \mathrm{subcutânea,} \mathrm{a} \mathrm{cada} \mathrm{oito} \mathrm{horas,} \mathrm{durante,}$ no mínimo, três dias.

As bandagens aplicadas do leito receptor foram oclusivas e não aderentes (primeira camada atadura de rayon ${ }^{5}$, segunda camada atadura de crepom $^{6}$, terceira camada Surgifix ${ }^{7}$ ). A troca de bandagens ocorreu diariamente até o sétimo dia de pós-operatório e, posteriormente, a cada três dias. Para a remoção, umedecia-se abundantemente o rayon com solução fisiológica, a fim de se evitar a movimentação do enxerto. Em seguida aplicava-se pomada de neomicinabacitracina $^{8}$. A partir do $15^{\circ}$ dia de pósoperatório, os animais permaneceram sem bandagem. Os pontos cutâneos foram removidos entre nove e 15 dias de pós-operatório.

Desenhos dos contornos dos enxertos foram realizados por sobreposição, com papel vegetal,

\footnotetext{
${ }^{4}$ MESH SKIN GRAFT EXPANDER ${ }^{\circledR}$ - Steel Bone System Com. Imp. Exp. de Materiais Médicos - Rua Itapeva, Bela Vista - São Paulo.

5 RAYON - Medi-House - Ind. Comércio e Produtos Cirúrgicos Hospitalares Ltda. - Rua Terezina, 451 - Vila Bertioga - São Paulo, SP.

${ }^{6}$ ATADURA DE CREPOM - Cremer - Rua Iguaçú, 291/363 - Blumenau, SC.

${ }^{7}$ SURGIFIX - Kors do Brasil Produtos Paramédicos Ltda., Rua Rui Barbosa, 95 - Conj. 82, Bairro Bela Vista - São Paulo, SP.

${ }^{8}$ NEBACETIN - Bik - Av. Casagrande, 850 - Diadema SP.
} 
aos três, sete, 15 e 30 dias de pós-operatório. Calculou-se a área de sobrevivência do enxerto pela medida das áreas não viáveis e total usandose fotomicroscopio Nikon conectado a um sistema de análise de imagem KS- $300^{9}$, cedido pelo Departamento de Patologia da Faculdade de Medicina de Botucatu. Foram consideradas como áreas não viáveis as que apresentaram coloração esbranquiçada, seroma, hematoma, necrose ou retração.

Para a avaliação microscópica, o enxerto, leito receptor e pele circundante adjacente foram colhidos em três animais aos sete, 15 e 30 dias de pós-operatório. $\mathrm{O}$ protocolo anestésico foi semelhante ao anteriormente citado. Após a fixação, os tecidos foram incluídos em parafina e processados. As lâminas foram coradas pelas técnicas de hematoxilina-eosina (HE) e tricômico de Masson.

Para as variáveis porcentagem de área de enxerto viável e não viável, os enxertos fixados com cola ou sutura foram comparados pela análise de medidas repetidas (Zar, 1996), uma vez que os indivíduos foram observados em vários momentos. As comparações foram realizadas ao nível de 5\% de significância.

\section{RESULTADOS}

A cola não teve suficiente poder adesivo para que o enxerto fosse fixado totalmente sem sutura. Houve retração do enxerto fixado com cola de fibrina, especialmente na borda ou canto proximal à articulação do cotovelo, em 87,7\% dos cães (Fig. 1a). Em ambos os tipos de fixação ocorreu intensa secreção serossanguinolenta entre as fendas do enxerto. As margens do enxerto que sobrepuseram as da ferida entraram em processo de necrose em torno de sete dias.

O enxerto viável apresentou-se róseo, ao passo que a porção não viável tornou-se esbranquiçada ou enegrecida. Nas fendas dos enxertos ocorreu

${ }^{9}$ MICROPHOT-FXA

Arq. Bras. Med. Vet. Zootec., v.56, n.3, p.312-319, 2004
MICROPHOT-FXA formação de tecido de granulação e posterior epitelização (Fig. 1b, Fig. 1c, Fig. 2). A presença de pêlos foi evidente aos 30 dias de pósoperatório.

Não houve diferença entre momentos de avaliação e técnicas de fixação quanto à área de enxerto viável (Tab. 1).

Tabela 1. Porcentagem média de área viável do enxerto, determinada por análise morfométrica, segundo técnica de fixação e momento de avaliação (período pós-operatório)

\begin{tabular}{lcccc}
\hline & \multicolumn{4}{c}{ Período pós-operatório } \\
\hline Técnica de & 3 dias & 7 dias & 15 dias & 30 dias \\
fixação do enxerto & & & & \\
Com cola & $91,1 \mathrm{Aa}$ & $87,9 \mathrm{Aa}$ & $75,7 \mathrm{Aa}$ & $91,4 \mathrm{Aa}$ \\
Sem cola & $95,7 \mathrm{Aa}$ & $81,7 \mathrm{Aa}$ & $85,2 \mathrm{Aa}$ & $82,8 \mathrm{Aa}$ \\
\hline Letras minúsculas distintas indicam diferença entre técnica de \\
fixação em cada & momento; letras maiúsculas distintas \\
indicam diferença entre momentos em cada técnica de \\
fixação.
\end{tabular}

Pela avaliação histológica no sétimo dia de pósoperatório, o enxerto fixado com sutura apresentou epitélio com aspecto normal, derme papilar e derme reticular com grande número de células inflamatórias e fibras colágenas em menor quantidade e de espessura mais delicada em relação ao enxerto fixado com cola de fibrina, que mostrou estágio mais avançado de reparação.

Com 15 dias de pós-operatório, a derme reticular do enxerto fixado com sutura mostrou-se menos densa e com grande número de células inflamatórias, aspecto mais vacuolizado, semelhante ao de sete dias (Fig. 3A). O enxerto fixado com cola apresentou estruturas basófilas arredondadas de diferentes diâmetros que originariam glândulas e folículos pilosos, derme papilar com características de tecido conjuntivo frouxo, grande número de fibroblastos ativos e fibras colágenas delicadas, grande quantidade de substância fundamental amorfa (Fig. 3B), derme reticular com aspecto mais denso e fibras colágenas mais grosseiras, evidenciando um processo de fibrose mais adiantado (Fig. 3B). 

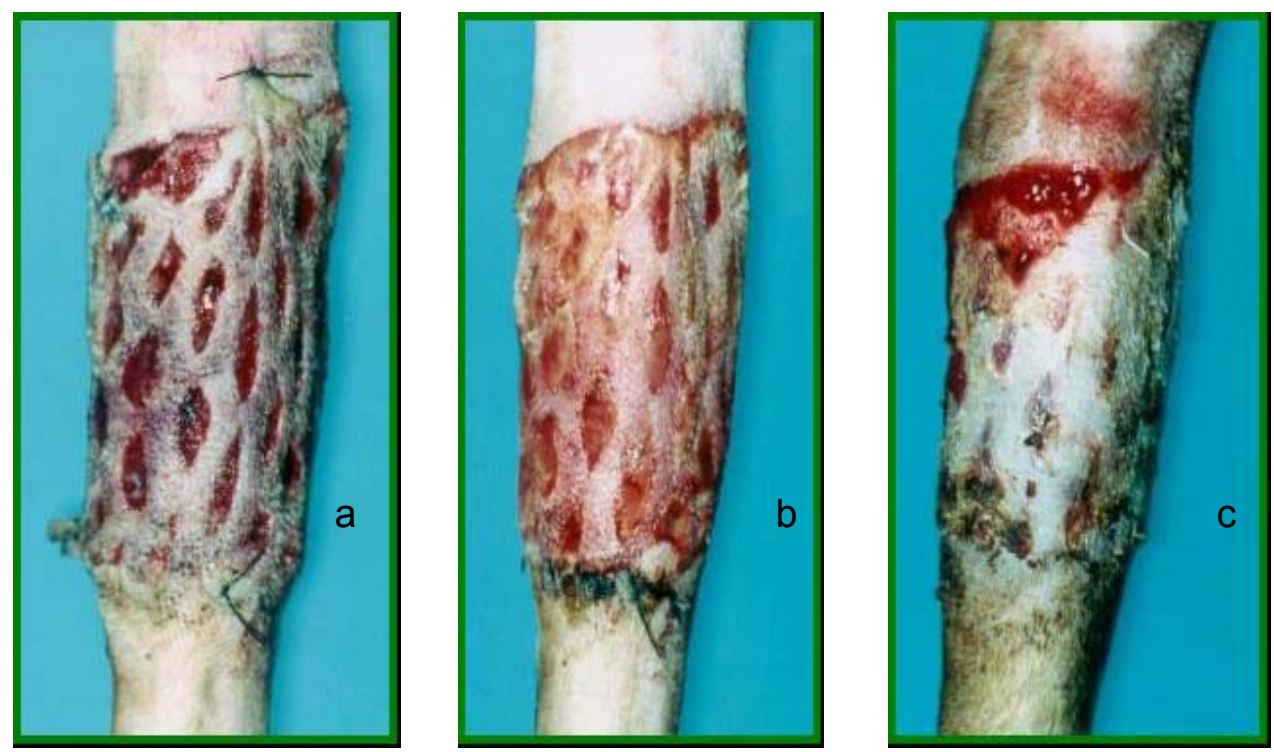

Figura 1 - Aspecto macroscópico no $3^{\circ}$ (a), $7^{\circ}$ (b) e $15^{\circ}$ (c) dias de pós-operatório do enxerto fixado com cola de fibrina, no tratamento de ferida induzida no antebraço direito. Verifica-se retração do canto proximal medial (a), fendas do enxerto com tecido de granulação (b) e posterior epitelização (c).
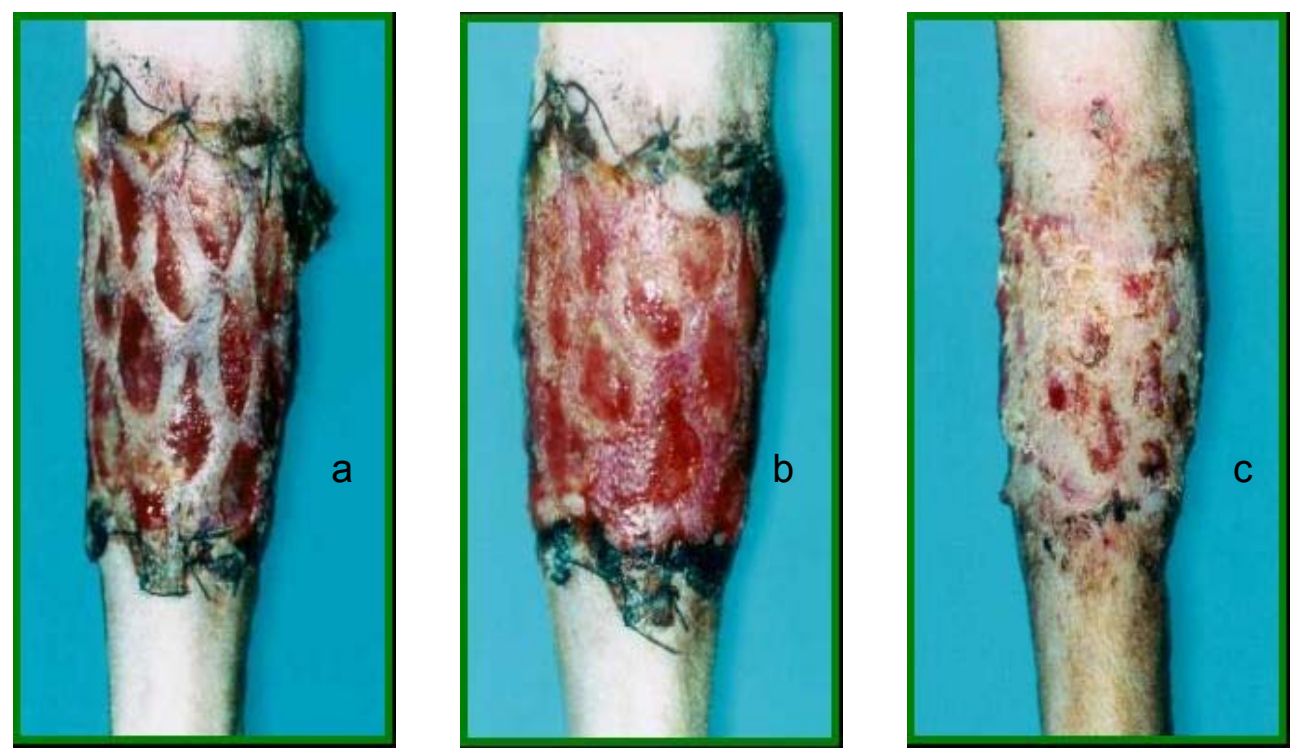

Figura 2. Aspecto macroscópico no $3^{\circ}(\mathrm{a}), 7^{\circ}$ (b) e $15^{\circ}$ (c) dias de pós-operatório do enxerto fixado apenas com sutura, no tratamento de ferida induzida no antebraço esquerdo. Observa-se, inicialmente, borda proximal medial com coloração clara (a), fendas do enxerto com tecido de granulação (b) e posterior epitelização (c). 

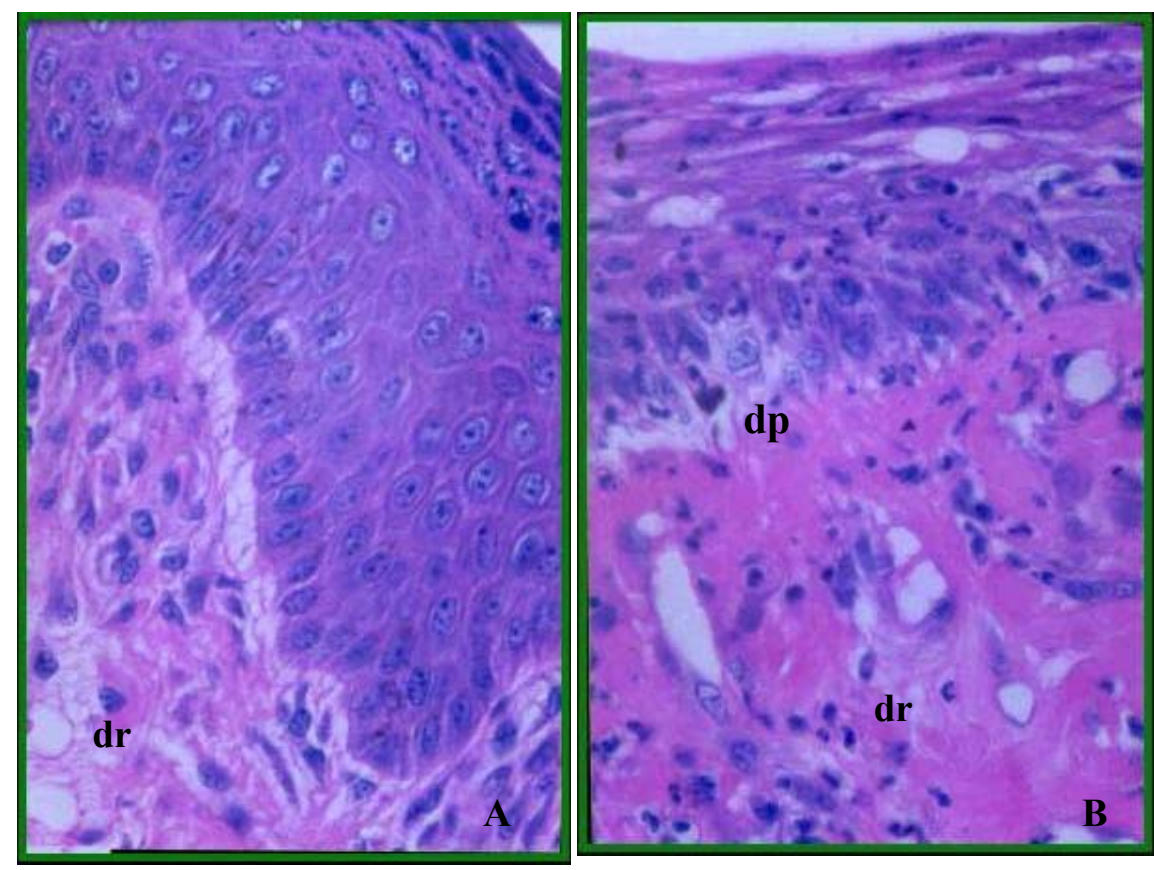

Figura 3. (A) Enxerto de pele fixado com sutura, com 15 dias de pós-operatório. Observa-se a derme reticular (dr) com grande número de células inflamatórias e moderada presença de fibroblastos e fibras colágenas. HE. 171,2X. (B) Enxerto de pele fixado com cola, com 15 dias de pós-operatório. Nota-se a derme papilar (dp), com características de tecido conjuntivo frouxo, grande quantidade de fibroblastos ativos e fibras colágenas delicadas. Derme reticular (dr) com aspecto denso e fibras colágenas grosseiras. HE. $171,2 \mathrm{X}$

No $30^{\circ}$ dia de pós-cirúrgico, o enxerto fixado com sutura apresentou menor número de fibras colágenas e maior quantidade de células inflamatórias nas dermes papilar e reticular, evidenciando estágio menos avançado de reparação tecidual em relação ao enxerto fixado com cola de fibrina. Esse apresentava dermes papilar e reticular com grande quantidade de fibras colágenas e menor número de células inflamatórias, caracterizando reparação em estágio mais evoluído, assemelhando-se ao normal.

\section{DISCUSSÃO}

O melhor período para a troca das bandagens é assunto controverso. No experimento optou-se pela troca precoce, apesar do risco da ruptura do selo de fibrina entre o leito recipiente e o enxerto (Pope, 1998), por causa do intenso volume de secreção observado na primeira semana. Swaim et al. (1984) também utilizaram trocas diárias de bandagens em experimento realizado em cães com enxerto em malha. Como citado por Hedlund (1997), o acúmulo de fluído pode ser pior do que o risco de movimentação por causar maceração do enxerto ou favorecer o crescimento de bactérias (Pope, 1988).

O baixo poder de adesão da cola de fibrina, em áreas de maior movimento, pode ser confirmado pela ocorrência de retração do enxerto somente na porção adjacente à articulação úmero-radial. Entretanto, o uso da cola reduziu o número de suturas e conseqüentemente o tempo cirúrgico (Saltz et al., 1991; Silver et al., 1995; Stolf, 1998), fato bastante significativo em pacientes de alto risco.

As fendas do enxerto em malha preveniram a formação de hematomas e seromas, que são causas freqüentes de perda de enxertos (Pope, 1990). Contudo, ao se comparar os métodos de 
fixação, não foi possível afirmar se houve ou não diferença na redução da coleção de fluídos (Lindsey et al., 1990) ou drenagem, pela ação hemostática da cola (Piechotta, Flemming, 1983; Lerner, Binur, 1990; Brennan, 1991).

O enxerto de espessura total permitiu melhor crescimento de pêlos do que o de espessura parcial (Probst, Peyton, 1986). No entanto, como foi utilizado o padrão em malha, as fendas cicatrizaram por epitelização e, conforme Pope (1990), resultaram em locais sem pêlo. Vale salientar que o crescimento de pêlos foi mais evidente com quatro semanas, enquanto Pope (1990) o observou de duas a três semanas. Embora não necessário para a sobrevivência (Pavletic, 1993), se os enxertos tivessem sido aplicados em leito de granulação saudável, a incorporação teria sido mais eficaz, visto que sua presença, de acordo com Swaim et al. (1984), é a melhor para enxertos em malha.

A área de enxerto viável não diferiu entre os enxerto fixados com cola ou com sutura, indicando que macroscopicamente não houve vantagem na utilização da cola. Pode ter ocorrido perda de parte do produto através das fendas do enxerto ou durante a troca das bandagens. Entretanto, pela análise histológica, os enxertos fixados com cola apresentaram estágio de reparação mais avançado em todos os momentos, sugerindo que o produto favoreceu a integração. Além disso, como referido por Brennan (1991), não foram observados sinais de reação de corpo estranho ou fibrose extensa associada ao uso da cola.

Foi possível concluir que a cola de fibrina derivada do veneno de serpente tem moderado poder adesivo e pela análise microscópica favorece a integração do enxerto cutâneo em malha de espessura total.

\section{AGRADECIMENTOS}

À Fundação de Amparo à Pesquisa do Estado de São Paulo (FAPESP) pelo apoio financeiro (no. 1999/08752-2) e ao "Center for the Study of Venoms and Venomous Animals" (CEVAP) pelo fornecimento da cola. Às doutoras Isolete A. Thomazini Santos e Maria José S. Mendes Giannini pela assistência.

\section{REFERÊNCIAS BIBLIOGRÁFICAS}

BRENNAN, M. Fibrin glue. Blood Rev., v.5, p.240-244, 1991.

HEDLUND, C.S. Skin grafts. In: FOSSUM, T.W. Small animal surgery. St. Louis: Mosby, 1997. p.128-132.

IUAN, F.C.; THOMAZINI, I.A.; GIANINI, M.J.M. et al. Reparation of peripheral nerves with fibrin glue prepared from snake venom. Preliminary results. São Paulo Med. J., v.113, p.100-102, 1995.

LERNER, R.; BINUR, N.S. Current status of surgical adhesives. J. Surg. Res., v.48, p.165181, 1990.

LINDSEY, W.H.; MASTERSON, T.M.; SPOTNITZ, W.D. et al. Seroma prevention using fibrin glue in a rat mastectomy model. Arch. Surg., v.125, p.305 -307, 1990.

PAVLETIC, M. Free grafts. In:__. Atlas of small animal reconstructive surgery. Philadelphia: Lippincott, 1993. chap.12, p.241 59.

PIECHOTTA, F.; FLEMMING, I. The maximization of wound healing with fibrin glue. Aesth. Plast. Surg., v.7, p.81-82, 1983.

POPE, E.R. Mesh skin graft. In: BOJRAB, M.J.; ELLISON, G.W.; SLOCUM, B. Current techniques in small animal surgery. 4.ed. Baltimore: Williams \& Wilkins, 1998. chap.37, p.603-607.

POPE, E.R. Mesh skin grafting. Vet. Clin. North Am., Small Anim. Pract., v.20, p.177-87, 1990.

POPE, E.R. Skin grafting in small animal surgery. Part II. Full-thickness skin-grafting techniques. Comp. Small Anim., v.10, p.10681077, 1988.

PROBST, C.W.; PEYTON, L.C. Enxertos de pele de espessura parcelada. In: BOJRAB, M.J. Cirurgia dos pequenos animais. São Paulo: Roca, 1986. cap.33, p.477-82.

SALTZ, R.; SIERRA, D.; FELDMAN, D. et al. Experimental and clinical applications of fibrin glue. Plast. Reconstr. Surg., v.88, p.1005-1015, 1991. 
SILVER, F.H.; WANG, M.; PINS, G.D. Preparation and use of fibrin glue in surgery. Biomaterials, v.16, p.891-903, 1995.

STOLF, H.O. Uso do adesivo tecidual de fibrina derivado do veneno de serpente e avaliação da técnica de auto-enxertia utilizando a pele do sulco nasogeniano. 1998. 103p. Tese (Doutor em Medicina) - Escola Paulista de Medicina, Universidade Federal de São Paulo, São Paulo.

SWAIM, S.F. Skin grafts. Vet. Clin. North Am., Small Anim. Pract., v.20, p.147-174, 1990.
SWAIM, S.F.; POPE, E.R.; LEE, A.H. et al. Evaluation of a practical skin grafting technique. J. Am. Anim. Hosp. Assoc., v.20, p.637-645, 1984.

VITERBO, F.; THOMAZINI, I.A.; GIANINI, M.J.S.M. Reparação de nervos periféricos com cola de fibrina derivada de veneno de cobra. Acta Cir. Bras., v.8, Supl.2, p.85, 1993.

ZAR, J.H. Biostatistical analysis. New Jersey: Prentice Hall, 1996. 718p. 